VERGARA, Esteban. "La investigación sin víctima de ilícitos cometidos en contextos de violencia doméstica. Su situación actual en los Estados Unidos de América y el aporte a los países integrantes del Sistema Interamericano de Derechos Humanos".

Polit. crim. Vol. 13, № 26 (Diciembre 2018) Art. 11, pp. 1055-1073.

[http://www.politicacriminal.cl/Vol_13/n_26/Vol13N26A11.pdf]

\title{
La investigación sin víctima de ilícitos cometidos en contextos de violencia doméstica. Su situación actual en los Estados Unidos de América y el aporte a los países integrantes del Sistema Interamericano de Derechos Humanos
}

The victimless prosecution of crimes committed in domestic violence contexts. Its current situation in the United States of America and the contribution to the member countries of the Inter-American System of Human Rights

\author{
Esteban María Vergara* \\ Secretario de la Fiscalía de Cámara Norte del Ministerio Público Fiscal \\ de la Ciudad Autónoma de Buenos Aires \\ evergara@fiscalias.gob.ar
}

\section{Resumen}

El presente artícuo pretende mostrar las dificultades que existen tanto en los Estados Unidos de América como en los países miembros del Sistema Interamericano de Derechos Humanos a la hora de investigar delitos cometidos en contextos de violencia doméstica y de género cuando la víctima no está presente en el juicio. En tal sentido, se realizará una aproximación a la situación de las víctimas de esos hechos, a las normas que rigen la materia y a los casos jurisprudenciales más influyentes de la Corte Suprema de los EEUU. Asimismo, se intentará cuestionar la situación actual en la que se encuentran los sistemas judiciales en nuestra región $\mathrm{y}$, finalmente, se invitará a encontrar soluciones.

Palabras clave: Violencia doméstica, violencia de género, investigación sin víctima, cláusula de confrontación, sistema acusatorio, Sistema Interamericano de Derechos Humanos.

\begin{abstract}
The present article attempts to show the difficulties that exist both in the United States of America and in the member countries of the Inter-American System of Human Rights when prosecuting crimes committed in domestic and gender violence contexts without the victim in trial. From there it provides an approximation to the situation of the victims of those offenses, to the rules that govern the subject and to the US Supreme Court's most influential case law. It also tries to question about the current situation of judicial systems in our region, and finally invites to find solutions to those inconveniences.
\end{abstract}

Key words: Domestic violence, gender violence, victimless prosecution, confrontation clause, accusatorial system, Inter-American System of Human Rights.

\section{Introducción}


Polit. crim. Vol. 13, No 26 (Diciembre 2018) Art. 11, pp. 1055-1073.

[http://www.politicacriminal.cl/Vol_13/n_26/Vol13N26A11.pdf]

De acuerdo a la Oficina de Estadísticas de la Justicia Norteamericana (Bureau of Justice Statistics $)^{1}$, sólo la mitad de las víctimas de violencia doméstica denuncian el delito sufrido ante la policía. Eso significa, sencillamente, que por cada caso judicializado existe otra mujer que sufre violencia desamparada en las sombras.

Son diversas las razones que dan las víctimas de estos hechos para no denunciarlos. Aproximadamente el $35 \%$ de aquellas mujeres, que no ventilaron el episodio de violencia sufrido, sostienen que se trata de cuestiones privadas o personales. El $7 \%$ lo considera un hecho de menor gravedad, que no reviste importancia. El 6\% piensa que la policía y el Estado no se molestarán en investigar su caso. Y el 3\% no lo denuncia para proteger al agresor.

Asimismo, de ese universo de casos sin judicializar casi un $20 \%$ de las mujeres víctimas reconoció que no había hecho la denuncia por miedo a que el agresor tome represalias. En efecto, se estima que el abusador, además, amenaza a la víctima en esos términos en aproximadamente la mitad de la totalidad de los casos que existen -denunciados y no denunciados-. También hay otros factores que llevan a no judicializar muchos episodios de violencia doméstica, como puede ser: la dependencia económica, el apego emocional, la existencia de hijos entre víctima y victimario -incluyendo el miedo a desarmar la familia o a que el Estado se entrometa en el destino de los menores- y la propia creencia desarrollada por la víctima de que el hecho sufrido no constituye delito alguno.

Pero la estadística más perturbadora para los actores del sistema judicial norteamericano -y que motiva este artículo- es que de aquel $50 \%$ de casos que sí son denunciados un $85 \%$ de sus víctimas se negará luego a declarar en juicio o perderá interés en la investigación, una vez que se haya disipado el episodio violento (y aun cuando éste pueda volverse a reeditar en un futuro próximo) $)^{2}$.

Este tipo de situaciones conducirá, probablemente, a la frustración del juicio con la consecuente impunidad del agresor, puesto que en sistemas de corte acusatorio difícilmente se pueda lograr una condena sin la presencia de la víctima en el proceso. Sucede que, como se explicará en los puntos subsiguientes, si el acusado no tiene o tuvo oportunidad de ejercer un contrainterrogatorio contra ella, su testimonio -por regla- no podrá ser valorado y, entonces, de no existir otra prueba, fracasará la acusación.

Lo inquietante también es que esa visión -inveterada en el sistema anglosajón- viene dándose de igual modo en la más elevada jurisprudencia moderna de nuestra región: de acuerdo con los criterios sentados por la Corte Interamericana de Derechos Humanos en un caso

Agradezco al Prof. Dr. Eduardo Javier Riggi por su valioso aporte al presente trabajo, sin el cual éste no habría sido posible.

${ }^{1}$ Departamento de Justicia de los EEUU, BJS, “Criminal Victimization Bulletin, 2016”, NCJ 251150, diciembre de 2017. Disponible en: https://www.bjs.gov/content/pub/pdf/cv16.pdf.

2 FISK, Andrew, "Prosecution of Domestic Violence Cases: The Practical Effects of the Ruling in Davis $v$. Washington", 126 S.Ct.2266 (2006), HeinOnline, 32 S. III. U. L.J. 251 2007-2008, Vol. 32, p. 264. En la Ciudad Autónoma de Buenos Aires la estadística es similar: de la totalidad de casos judicializados en el año 2009, el $83 \%$ de ellos fue archivado por insignificancia o falta de prueba del hecho (Ministerio Público Fiscal de la CABA, Res. FG. $n^{\circ}$ 16/10). 
VERGARA, Esteban. "La investigación sin víctima de ilícitos cometidos en contextos de violencia doméstica. Su situación actual en los Estados Unidos de América y el aporte a los países integrantes del Sistema Interamericano de Derechos Humanos”.

relativamente reciente, el acusado y su defensa tienen que tener la posibilidad de controlar, examinar o contrainterrogar al testigo en cuyas declaraciones se funda la acusación o la condena $^{3}$. De lo contrario, según dichos estándares, se violaría su derecho de defensa ${ }^{4}$.

En consecuencia, si se aplica esa doctrina al tema de este trabajo nos situamos, en principio, ante la imposibilidad de incorporar por lectura declaraciones testimoniales al juicio ${ }^{5}$. Por tales motivos, si la víctima no se llegara a presentar en el debate, y no se contara con su testimonio formalizado de manera compatible con el derecho al contrainterrogatorio, lo más probable es que no se pueda sostener la acusación por falta de elementos incriminantes, con el consecuente naufragio del proceso.

Ahora bien, en materia de violencia doméstica aquellas prerrogativas merecen especial atención. Esto porque, a diferencia de lo que ocurre con otra clase de delitos, la mayoría de sus víctimas desisten las denuncias formuladas y, además, porque este tipo de hechos no suelen contar con testigos presenciales que permitan prescindir de aquéllas al tener lugar en la intimidad.

\section{El desistimiento de las víctimas durante el proceso}

Para dimensionar la trascendencia de la situación, en los Estados Unidos de América, como se dijo, ocho de cada diez casos de violencia doméstica que no lograron condena culminaron de esa manera porque la víctima decidió no cooperar con el proceso, según expone el Departamento de Justicia de ese país ${ }^{6}$.

En nuestra región, estudios de campo indicaron que en la Ciudad Autónoma de Buenos Aires el 83\% de los casos denunciados durante el año 2016 fueron archivados, por falta de prueba mayormente (46,34\%), ante la ausencia de la víctima en el juicio y la inexistencia de otros elementos que sostengan la acusación ${ }^{7}$. En Chile, por su parte, la deserción fue de un 49,3\%; porcentaje en el que influyen los cambios posteriores en la actitud del agresor y los complejos

\footnotetext{
${ }^{3}$ Corte IDH, caso “Castillo Petruzzi c. Perú”, sentencia del 30/05/1999. Estos criterios fueron recogidos en gran medida de las sentencias del Tribunal Europeo de Derechos Humanos en: TEDH, caso "Unterpertinger vs. Austria”, serie A, n 110, sentencia del 24/11/1986; caso “Barberá, Messegué y Jabardo vs. España”, serie A, n 146, sentencia del 6/12/1988; caso "Säidi vs. Francia”, serie A, n 261-C, sentencia del 20/09/1993. Asimismo, fueron receptados por la Corte Suprema de Argentina in re "Recurso de hecho deducido por la defensa de Aníbal Leonel Benitez en la causa 'Benitez, Aníbal Leonel s/lesiones graves”, causa $\mathrm{n}^{\circ} 1524$, sentencia del 12/12/2006.

${ }^{4}$ PIDCyP, art. 14.3.e; CADH, art. 8.2.f;

${ }^{5}$ Aunque cabría pensar en la formalización excepcional de ese tipo de testimonios donde se le permitiera a la defensa confrontar al testigo a fin de que sean introducidas válidamente por lectura.

${ }^{6}$ Departamento de Justicia de los EEUU, BJS, Special Report: "State Court Processing of Domestic Violence Cases", NCJ 214993, febrero de 2008.

${ }^{7}$ Ministerio Público Fiscal de la CABA, Res. FG. n $16 / 10$.
} 
Polit. crim. Vol. 13, No 26 (Diciembre 2018) Art. 11, pp. 1055-1073.

[http://www.politicacriminal.cl/Vol_13/n_26/Vol13N26A11.pdf]

trámites del proceso iniciado ${ }^{8}$. En Bolivia, el número asciende al alarmante $71 \%$ de casos archivados por carecer de otras pruebas, luego de que las víctimas los denunciaran ${ }^{9}$.

Estos desistimientos o faltas de colaboración encuentran explicación. Humildemente se intentará abordar sus causales, muchas de ellas pertenecientes a otras ciencias, a los fines de conocer por qué sucede aquello, al menos someramente.

Primero, es sabido que este tipo de casos violentos presenta factores estáticos y dinámicos. Muchas veces estos últimos -por su propia naturaleza cambiante- son los que llevan a las víctimas a abandonar sus primigenias denuncias. En ese sentido, se habla del síndrome de la mujer maltratada ${ }^{10}$ o de la tendencia de las víctimas de violencia doméstica a retractarse de su testimonio o a negarse a testificar (battered women's syndrome or domestic violence victims' tendency to recant their testimony or refuse to testify $)^{11}$.

En efecto, las situaciones de violencia doméstica nacen con una escalada paulatina -a veces imperceptible- que torna a sus víctimas cada vez más vulnerables. Tienen una forma cíclica que intercala períodos de calma y afecto hasta llegar a situaciones que pueden poner en peligro la vida. La investigadora norteamericana Leonore Walker describió en 1979 este proceso que denominó el Ciclo de la violencia y que se compone de tres fases: todo comienza con una parte silenciosa, de escalada gradual, que se caracteriza por el aumento de conflictos y actos violentos, por lo general verbales y en menor medida físicos, con cambios repentinos de ánimo que la mujer no llega a comprender o que justifica ya que no es consciente del proceso de violencia en el que se encuentra inmersa. La víctima intenta complacer al agresor para evitar esos conflictos en la creencia de que son temporales $\mathrm{y}$, muchas veces, pensando equivocadamente que son por su propia culpa. Esta primera etapa Walker la denomina Fase de acumulación de tensión. Luego sigue una etapa conocida como Fase de agresión, donde estalla la violencia en todas sus formas: física, psicológica y/o sexual. Se producen estados de ansiedad y temor en la víctima, miedos fundados en situaciones extremas que llevan recién aquí- a consultar con allegados, familiares o incluso autoridades para denunciar al agresor y poner fin a la situación. Sin embargo, antes de que esto ocurra llega finalmente lo que Walker define como Fase de conciliación o de luna de miel: superados los episodios violentos, el agresor suele pedir perdón, mostrarse amable e incluso cariñoso, y promete que aquello no volverá a suceder. Además, justifica la agresión con otros problemas que él sufre y que le son ajenos -en muchos casos señalando a ella como la responsable de sus brotes violentos-, y le expresa a su víctima cuánto la quiere. Con estas manipulaciones el agresor conseguirá que su pareja -muchas veces deseosa de que él cambie-se convenza de que no

\footnotetext{
${ }^{8}$ BINSTOK, Hanna, "Violencia en la pareja", Serie Mujer y Desarrollo, n 23 (1998), p. 30, en: https://repositorio.cepal.org/bitstream/handle/11362/5896/1/S026408_es.pdf.

${ }^{9}$ Relatoría sobre los Derechos de la Mujer de la CIDH-OEA, informe "Acceso a la Justicia para las Mujeres Víctimas de Violencia en las Américas”. OEA/Ser.L/V/II, Doc. 68, 20 de enero de 2007.

${ }^{10}$ Ministerio Público Fiscal de la CABA, Fiscalía de Cámara Norte, Dictamen n 355/DIC-FCN/15.

${ }^{11}$ PERCIVAL, Jeanine, "The price of silence: The prosecution of domestic violence cases in light of Crawford v. Washington", Southern California Law Review Domestic Violence, Vol. 79:213, p. 216.
} 
VERGARA, Esteban. "La investigación sin víctima de ilícitos cometidos en contextos de violencia doméstica. Su situación actual en los Estados Unidos de América y el aporte a los países integrantes del Sistema Interamericano de Derechos Humanos”.

fue para tanto, que mire su parte amorosa y que crea que podrá ayudarlo a cambiar. Sin embargo, ésta es sólo una fase más del Ciclo, el cual volverá a iniciarse ${ }^{12}$.

En otro orden de cosas, deben resaltarse los factores vinculados al sistema de administración de justicia y, muchas veces, a la deficiente investigación de los casos por parte de los actores judiciales. Al menos de México para abajo, la $\mathrm{CIDH}$ resalta la revictimización de la mujer como causa principal de su desistimiento, que se da cuando se la somete constantemente a actos procesales que reiteran las vivencias sufridas o muestran mayor interés en su vida privada que en el esclarecimiento de los hechos y la sanción de los responsables ${ }^{13}$. De esta forma, señala el organismo, algunas autoridades administrativas y judiciales no responden con la debida seriedad y diligencia para investigar, procesar y sancionar a los responsables. Estas situaciones terminan por alejar a las víctimas de los procesos, con el consabido resultado.

Asimismo, se ha advertido que muchas veces los procedimientos comprometen directamente el acceso a la justicia de las víctimas cuando se dirigen a evaluar la conducta de éstas en lugar de considerar el contexto de coercibilidad en que ocurrieron los hechos así como las evidencias indirectas. Del mismo modo, se han constatado casos en donde se ha inferido el consentimiento de la víctima a la situación violenta, así como otros en donde se ha reducido la credibilidad de su testimonio por su comportamiento previo o posterior al hecho ${ }^{14}$. Estas prácticas también propenden al rechazo del sistema por parte de las mujeres, lo que muchas veces se traduce en escepticismo y otras tantas en el abandono de los procedimientos por encontrar resistencia o falta de contención.

De lo expuesto se advierte que las dificultades a la hora de investigar y probar delitos cometidos en este tipo de contextos no son pocas, tanto en los Estados Unidos como en nuestras latitudes. Y si a eso le agregamos determinadas reglas y decisiones jurisprudenciales que imperan en el país nórdico, la situación se torna aún más dificultosa.

El procedimiento angloparlante presenta una particularidad en la utilización y valoración de los testigos, fuertemente arraigada desde los orígenes del Common Law. Como regla, el interrogatorio está dividido en dos partes: el examen directo y el contrainterrogatorio. El examen directo es el que realiza la parte que ofreció al testigo en primer orden (donde lógicamente éste saldrá victorioso del cuestionario) y el contrainterrogatorio es el que ejercerá luego la contraparte (donde intentará vencerlo). El objeto de la repregunta es poner a prueba la credibilidad del testigo, modificar o explicar lo que éste expuso en el primer

\footnotetext{
12 Publicación del Programa "Mujeres sin violencia” del Gobierno de la República de México, en www.gob.mx/mujeressinviolencia/articulos/comprender-el-circulo-de-la-violencia-es-el-primer-paso-pararomperlo.

13 Relatoría sobre los Derechos de la Mujer de la CIDH-OEA, informe “Acceso a la Justicia para las Mujeres Víctimas de Violencia en las Américas”. OEA/Ser.L/V/II, Doc. 68, 20 de enero de 2007, párr. 19.

${ }^{14}$ Comité de Expertas/os (CEVI) del Mecanismo de Seguimiento de la Implementación de la Convención Interamericana para Prevenir, Sancionar y Erradicar la Violencia Contra la Mujer, "Convención de Belém do Pará" (MESECVI). "Declaración sobre la Violencia contra las Mujeres, Niñas y Adolescentes y sus Derechos Sexuales y Reproductivos”. OEA/Ser.L/II.7.10 MESECVI/CEVI/DEC.4/14. Del 19/09/14.
} 
Polit. crim. Vol. 13, No 26 (Diciembre 2018) Art. 11, pp. 1055-1073.

[http://www.politicacriminal.cl/Vol_13/n_26/Vol13N26A11.pdf]

examen o, directamente, desacreditarlo. Este procedimiento tiene por fin último, conforme a las raíces del sistema inglés, alcanzar la verdad y por ello se le asigna una enorme importancia. En efecto, la American Jurisprudence ${ }^{15}$ lo ha definido como el test más elevado y más indispensable desarrollado por el Common Law para el descubrimiento de la verdad. Por lo mismo, se considera que el derecho a repreguntar es absoluto y no un mero privilegio: se trata de un derecho fundamental básico en el sistema anglosajón y elemental en su definición de juicio justo ${ }^{16}$.

Por ello, se ha llegado a concluir que el derecho a un juicio justo puede resumirse, en esencia, en el derecho a una oportunidad real de defenderse contra las acusaciones que se le dirigen. La posibilidad de confrontar y repreguntar a los testigos ha sido reconocida como parte esencial de los derechos de defensa y del debido proceso (due process) ${ }^{17}$. Producto de esto es la cláusula de confrontación, establecida en la Sexta Enmienda a la Constitución de los Estados Unidos de América.

A continuación se explicará dicha cláusula de confrontación y se analizará cómo la jurisprudencia norteamericana ha hecho jugar su aplicación a fin de logar comprender su alcance. Luego, se intentará determinar si la evolución jurisprudencial permitió allanar el camino de los órganos encargados de la persecución penal o dificultarlo aún más tal como sostiene gran parte de la doctrina de aquél país ${ }^{18}$.

\section{La cláusula de confrontación}

Desde los tiempos del célebre juicio contra Sir Walter Raleigh en Inglaterra que el sistema acusatorio anglosajón intenta erradicar "los males de los juicios del derecho continental" como alguna vez lo definió la Corte Suprema de los Estados Unidos ${ }^{19}$ - y en concreto el uso de pruebas ex parte contra el acusado. En 1618, Sir Raleigh fue condenado y decapitado en Westminster por encontrárselo culpable de traición, por conspirar contra la Corona Británica en la famosa "Invencible Inglesa" o "Contraarmada". Para llegar a esa decisión, el tribunal que lo enjuició valoró como prueba en su contra una declaración jurada -escrita y extrajudicial- de un Lord inglés, quien afirmaba su culpabilidad a partir de los dichos que habían llegado a sus oídos de un gentleman portugués jamás identificado (a quien Raleigh definió como un "miserable mendigo" y "jesuita salvaje”).

Este caso fue señalado como un "episodio vergonzoso" en la historia del derecho inglés ${ }^{20}$ y el puntapié para la conformación del sistema probatorio como hoy se lo conoce. La cláusula

\footnotetext{
${ }^{15}$ El Prof. Luis María Bunge Campos define a esta publicación de carácter oficial como una enciclopedia que, por su monumental envergadura, no tiene parangón alguno con nuestra literatura jurídica. Infra nota $\mathrm{n}^{\circ} 16$

${ }^{16}$ BUNGE CAMPOS, Luis María, “Cross Examination”, Lecciones y Ensayos, n 63, p. 46 y ss., en: http://www.derecho.uba.ar/publicaciones/lye/revistas/63/cross-examination.pdf.

${ }^{17}$ Corte Suprema de los Estados Unidos de América, caso Chambers v. Mississippi, 1973 (410 US. 284).

18 Vgr. CRUMP, David, “Overruling Crawford v. Washington: Why and How”, Notre Dame L. Rev. 115 (2012), p. 115-157.

19 Corte Suprema de los Estados Unidos de América, caso Crawford v. Washington, 541 U.S. 36 (2004).

20 541 U.S. 36 (2004).
} 
VERGARA, Esteban. "La investigación sin víctima de ilícitos cometidos en contextos de violencia doméstica. Su situación actual en los Estados Unidos de América y el aporte a los países integrantes del Sistema Interamericano de Derechos Humanos”.

de confrontación nació, tiempo más tarde, como consecuencia de este largo proceso de diferenciación del derecho continental, desterrado con la conclusión del dominio romano en su territorio ${ }^{21}$, y fue finalmente incorporado por los Framers $^{22}$ al sistema acusatorio norteamericano como un elemento fundamental.

Hoy en día, la Sexta Enmienda a la Constitución de los Estados Unidos de América establece cinco derechos esenciales del acusado en un juicio criminal. Estos son: 1. A un juicio rápido y justo; 2. A ser juzgado por un jurado imparcial; 3. A ser informado sobre los cargos en su contra; 4. A convocar a testigos y confrontar los contrarios; y 5 . A un abogado 23

Del cuarto principio se deriva la denominada cláusula de confrontación ${ }^{24}$, que implica que todo acusado debe tener la oportunidad de enfrentar a los testigos que declaren en su contra y efectuarles preguntas y repreguntas (en el derecho anglosajón se lo llama crossexamination $^{25}$ ). Asimismo, para el ejercicio pleno de este derecho se establece que los testigos deben declarar en la audiencia pública con la presencia de todas las partes, ya que en caso contrario el testimonio (sin importar cómo o cuándo fue obtenido) no podrá valorarse en contra del acusado. De este modo, se busca asegurar el respeto al debido proceso y derecho de defensa en juicio ("the right to be confronted with the witnesses against him, to have compulsory process for obtaining witnesses in his favor, and to have the assistance of counsel for his defense" ${ }^{\text {"26). }}$.

Veamos un ejemplo que suele darse con frecuencia: se enjuicia a una persona por el delito de hurto. Durante la investigación preliminar, el fiscal logra colectar la versión de un testigo presencial del hecho que luego enferma y, finalmente, muere antes de que el acusado o su defensor puedan contrainterrogarlo (ejercer el cross-examination). Llegado el juicio, el fiscal incorpora en su alegato el testimonio recogido por escrito y aclara la imposibilidad de convocarlo en virtud de su fallecimiento. Siendo así las cosas, por imperio de la cláusula de confrontación, el juez ordena la eliminación del contenido de ese testimonio de los registros del debate e instruye al jurado a no considerarlo como prueba. Si bien es cierto que no existe responsabilidad alguna de parte del acusador público en la ausencia del testigo en el juicio,

${ }^{21}$ RUBANO LAPASTA, Mariela, "El sistema del Common Law en el derecho inglés y el derecho de los Estados Unidos de América", Revista de la Facultad de Derecho, Universidad de la República, Uruguay, p. 70, en: revista.fder.edu.uy/index.php/rfd/article/download/268/291.

${ }^{22}$ Como se denomina a los constituyentes norteamericanos.

23 "En toda causa criminal, el acusado gozará del derecho de ser juzgado rápidamente y en público por un jurado imparcial del distrito y Estado en que el delito se haya cometido, distrito que deberá haber sido determinado previamente por la ley; así como de que se le haga saber la naturaleza y causa de la acusación, de que se le caree con los testigos que depongan en su contra, de que se obligue a comparecer a los testigos que le favorezcan y de contar con la ayuda de un abogado que lo defienda". Traducción oficial, disponible en https://www.archives.gov/espanol/constitucion.html. El destacado me pertenece.

24 En inglés, Confrontation Clause.

25 Sobre esta técnica de interrogación, para mayor abundamiento ver: en español: www.derecho.uba.ar/publicaciones/lye/revistas/63/cross-examination.pdf; en inglés: www.americanbar.org/groups/public_education/resources/law_related_education_network/how_courts_work/ crossexam.html

${ }^{26}$ De la redacción original de la VI Enmienda a la Constitución norteamericana. 
Polit. crim. Vol. 13, № 26 (Diciembre 2018) Art. 11, pp. 1055-1073.

[http://www.politicacriminal.cl/Vol_13/n_26/Vol13N26A11.pdf]

la circunstancia de que la defensa no pueda confrontarlo es suficiente para declarar su improcedencia. Incluso, el juez puede interrumpir el juicio (declarando un mistrial ${ }^{27}$ ) y ordenar la realización de un nuevo debate desde cero, si el testimonio incorporado por lectura fuera de una trascendencia tal que difícilmente los miembros del jurado puedan realmente eliminarlo de sus mentes y no se pueda asegurar que, si bien fue excluido de las constancias del juicio, no vaya a influenciarlos a la hora de dictar el veredicto ya que, a pesar de su eliminación, finalmente fue escuchado por ellos.

De lo expuesto, se advierte la trascendencia de esta cláusula en casos de violencia doméstica. Ello toda vez que, como se señaló más arriba, el único testimonio que en la mayoría de este tipo de casos existe para probarlos suele ser el de la propia víctima, quien, a su turno, muchas veces desiste de continuar adelante con su denuncia o se niega a declarar en juicio ${ }^{28}$. Sucede que, en resumidas cuentas, la denuncia efectuada por la víctima a las autoridades no puede sostenerse como prueba, por lo que la acusación se caerá y el hecho deberá quedar impune.

Si bien existen determinadas excepciones a la cláusula de confrontación o particularidades en el modo de aplicarla, ninguna parece ser suficiente a los fines apuntados en este trabajo. Un ejemplo de ello son los casos de violencia sexual contra menores de edad ya que por las características especiales de las víctimas y las dificultades a la hora de recibirles testimonio, todo llevaría a indicar la conveniencia de su prescindencia. Sin embargo, esta posibilidad de omitir su declaración no ocurre. Legisladores estadounidenses a nivel estatal sancionaron en tiempos recientes ciertas normas que armonizan esas dificultades con la cláusula, al menos en parte. En tal sentido, para que los acusados no queden impunes cuando los menores víctimas tengan miedo de declarar frente a ellos (como ocurre en la mayoría de los casos), varios Estados autorizaron el testimonio del menor fuera de la sala del tribunal, en habitaciones especialmente diseñadas, mediante la grabación fílmica en circuitos cerrados y donde el imputado puede ver al testigo, pero no a la inversa. Algo similar a lo que en Argentina se conoce como "Cámara Gesell", recogido en diversas normas nacionales y locales que encuentran fundamento en la Convención Americana de los Derechos del Niño ${ }^{29}$.

Tal vez no sea ésta la mejor solución, pero, en definitiva, no se debe olvidar que la cláusula de confrontación fue incorporada expresamente al Bill of Rights ${ }^{30}$ norteamericano y que no es una derivación o norma procesal producto de un derecho superior que pueda adecuarse

\footnotetext{
27 El término mistrial refiere a un juicio que no puede ser completado o cuyo resultado no tiene valor legal, usualmente en virtud de errores o inobservancias legales, de acuerdo con la definición dada por el Cambridge Dictionary (http://dictionary.cambridge.org).

28 Debe señalarse también que, además de los motivos íntimos que llevan a las víctimas a desistir o negarse a declarar vistos anteriormente, existen en el derecho anglosajón determinadas normas que les permiten legalmente tomar aquellas decisiones sin que puedan ser forzadas a hacer lo contrario. Tal por caso el denominado spousal privilege (facultad de abstención en razón del vínculo) cuando víctima y victimario son pareja.

${ }^{29}$ En ese sentido, véase el art. 250 bis y quater del Código Procesal Penal de la Nación; el art. 43 del Régimen Procesal Penal Juvenil de la Ciudad Autónoma de Buenos Aires; y el art. 2.2. de la Convención Americana de los Derechos del Niño.

${ }^{30}$ Como se conoce a las diez primeras enmiendas a la Constitución norteamericana.
} 
VERGARA, Esteban. "La investigación sin víctima de ilícitos cometidos en contextos de violencia doméstica. Su situación actual en los Estados Unidos de América y el aporte a los países integrantes del Sistema Interamericano de Derechos Humanos”.

según cada caso, sino que fue tallada en piedra, tal cual es, en la enmienda relativa a las garantías judiciales.

Sin embargo, su alcance no quedó libre de interpretaciones. Ello explica que en el último tiempo surgieran diversos fallos de la Corte Suprema de los Estados Unidos que intentaron explicar cómo debe ser entendida y aplicada -a pesar de lo cual ninguno de ellos quedó exento de críticas doctrinales, incluso cuentan con disidencias de los mismos integrantes del tribunal-. Desde ya se adelanta que esos fallos no brindaron soluciones a las dificultades existentes en la persecución y castigo de este tipo de casos, sino todo lo contrario.

\section{Los casos más trascendentes de la Corte Suprema de los Estados Unidos de América en relación al alcance de la cláusula de confrontación}

Durante mucho tiempo existió lo que en el derecho angloparlante se llamó Evidence-basedprosecution o Victimless prosecution (investigación/enjuiciamiento basado únicamente en evidencia no testimonial o sin la víctima). Este modo de proceder permitía investigar y lograr condenas prescindiendo del testimonio de la víctima en el juicio, en casos determinados como podrían ser los que enmarcan el presente artículo (ilícitos cometidos en contextos de violencia doméstica). Para comprobar que su procedencia no violara la cláusula de confrontación existía una herramienta a la hora de analizar la viabilidad de incorporar este tipo de pruebas -los testimonios no-confrontados- y sopesarlos al dictar sentencia, conocida en la práctica como el test de Roberts o Roberts test (llamada así en virtud de un fallo homónimo ${ }^{31}$ que fuera leading case hasta que se lo dejó de lado, como veremos). Mediante este test de procedencia se lograba utilizar el testimonio de aquéllos que luego no podían declarar en el debate (por el motivo que fuere) siempre y cuando la declaración obtenida previamente y sin control de las partes presentara serios visos de confiabilidad (llamado indicia of reliability). Algo ambiguo y difícil de aplicar en la mayoría de los casos, pero, cuanto menos, era una salida que, no sin esfuerzo mediante, permitiría avanzar eventualmente en determinados juicios.

Imaginemos, por ejemplo, un episodio de violencia doméstica ocurrido en la intimidad, sin testigos, que culmina con la muerte de la víctima luego de cierta agonía. Sin aquella herramienta, la versión que ella pudo dar camino al hospital antes de fallecer no podría utilizarse. En cambio, si ese mismo testimonio es ratificado por los dichos de los enfermeros de la ambulancia en el debate y se suma al del policía que llegó hasta el lugar del hecho y escuchó lo que ella decía, al tamizarlo mediante el Roberts test podría superarse el examen de confiabilidad y concluirse: que presenta indicios concretos y fiables de veracidad. Así, su utilización estaría permitida como una prueba más, independientemente de la valoración o peso que luego corresponda darle en virtud de su indirecta incorporación al juicio.

Al respecto, para una mejor comprensión, debe aclararse que, en rigor, los tribunales anglosajones utilizan diversos términos para describir la naturaleza de las pruebas testimoniales que no responden necesariamente a la traducción literal de los que utilizamos en Iberoamérica ni significan lo mismo procesalmente hablando y, por tanto, carecen del

${ }^{31}$ Ohio v. Roberts, 448 U.S. 56 (1980). 
Polit. crim. Vol. 13, No 26 (Diciembre 2018) Art. 11, pp. 1055-1073.

[http://www.politicacriminal.cl/Vol_13/n_26/Vol13N26A11.pdf]

mismo peso. En ese sentido, pueden referirse indistintamente a statement (vocablo genérico que alude a cualquier tipo de dichos en cualquier contexto, pudiéndosela traducir como manifestación), testimonial (término que habla de la naturaleza del acto sin perjuicio de su forma: puede ser la declaración testimonial como la conocemos nosotros, pero además usado para cualquier otra prueba que dé fe de algo, como un informe), eyewitness (testigo presencial, que conoce a través de sus sentidos), hearsay (testigo o testimonio de oídas, o no presencial, que sabe porque le contaron), affidavit (término específico que alude a una declaración que se hace bajo juramento, ante funcionario que da fe del acto y que cumple ciertas formalidades rígidas), entre otros. Así, la versión de la víctima obtenida indirectamente en el ejemplo antes dado podría igualmente incorporarse al plexo probatorio del debate como un hearsay statement, a través de quienes escucharon lo que dijo sobre lo ocurrido. De todos modos, a los fines del presente análisis, bastará con concentrarse en la declaración testimonial como la conocemos en estas latitudes, con las formalidades comunes a los distintos ordenamientos procesales que conviven en nuestra región.

Por último, conviene recordar la importancia de la jurisprudencia en el sistema judicial de los Estados Unidos como fuente de derecho, a la que se suele denominar case law. De allí que en la tradición del Common Law es imprescindible que las partes tengan acceso a sentencias anteriores para diseñar sus argumentos en el marco de los precedentes pertinentes para la preparación del juicio, en virtud del stare decisis que dota al servicio de justicia de una mayor seguridad al tornarse previsibles las soluciones de los casos que les son sometidos $^{32}$.

\subsection{Crawford v. Washington ${ }^{33}$}

Como se adelantó, aquella forma de llevar adelante los casos y validar prueba recibida indirectamente sin violar la cláusula de confrontación no duró para siempre. El caso Roberts dejó de ser un precedente obligatorio (stare decisis) con el dictado del tristemente célebre fallo Crawford, considerado un hito que puso fin a una era y dio comienzo a otra nueva en la jurisprudencia vinculada a la cláusula y, consecuentemente, en la investigación de hechos cometidos en un marco de violencia doméstica.

En el caso Crawford, una persona había sido apuñalada en su departamento. La policía arrestó a Michael Crawford y a su esposa Sylvia por considerarlos sospechosos de cometer el crimen. Al interrogarlos separadamente, Sylvia brindó una versión que indicaba que Michael no había actuado en legítima defensa (era su descargo), sino que había asesinado directamente a la víctima de manera premeditada. En el juicio, ella se negó a brindar su testimonio en virtud del spousal privilege ${ }^{34}$ por lo que la fiscalía intentó hacer valer el descargo grabado que brindó en la primera oportunidad. La defensa de Michael se opuso a ello esgrimiendo la violación a la cláusula de confrontación, pues se le impedía examinar a la testigo. El tribunal de grado rechazó su oposición y aprobó la incorporación del testimonio

\footnotetext{
32 POPKIN, Margaret, Directora Ejecutiva de la Fundación para el Debido Proceso Legal, Washington, D.C., en "La difusión de las sentencias en Estados Unidos", ponencia presentada en Sinaloa y Tabasco, 2004, en: https://archivos.juridicas.unam.mx/www/bjv/libros/4/1646/10.pdf

33541 U.S. 36 (2004).

${ }^{34}$ Facultad legal de abstención en razón del vínculo.
} 
VERGARA, Esteban. "La investigación sin víctima de ilícitos cometidos en contextos de violencia doméstica. Su situación actual en los Estados Unidos de América y el aporte a los países integrantes del Sistema Interamericano de Derechos Humanos”.

grabado, pues su soporte físico era suficiente indicio de confiabilidad y garantía de veracidad de su contenido (según las reglas del Roberts test). El tribunal condenó a Michael Crawford y la Corte de Washington ratificó esa condena.

Sin embargo, la Corte Suprema de los Estados Unidos revocó el fallo condenatorio y absolvió al imputado. Esto pues -dejando de lado por primera vez el caso Roberts- entendió que ese proceder probatorio violaba la Sexta Enmienda a la Constitución norteamericana. Llegar a esa conclusión y desterrar años de jurisprudencia en sentido contrario no fue fácil. Ello, al punto tal que el extenso precedente en ciernes debió examinar la historia de la cláusula de confrontación, en especial sus raíces en el Common Law de Inglaterra y su fundamentación en contra del Civil Law continental ${ }^{35}$.

El caso brindó muchos análisis y conclusiones. Pero, en esencia, el principal motivo para desacreditar el precedente Roberts fue que éste, al autorizar la prescindencia de la confrontación, permitió la incorporación de pruebas que tornaban obvia la culpabilidad del acusado -según el voto del Juez Scalia, considerado el autor intelectual de esta doctrina-. Es decir, el debate perdía sentido si su objeto era incorporar pruebas indiscutibles que, de antemano, ya se sabía hacia dónde apuntaban. Entonces, aquello tornaba inútil cualquier juicio entendido como debate oral y contradictorio entre las partes para determinar la culpabilidad o inocencia de un acusado. Por todo esto, el fallo señaló que la cláusula había nacido, alguna vez, para excluir esas injusticias y darle plenitud a la confrontación en juicio y, por tal motivo, había llegado la hora de ponerla en su lugar.

En resumidas cuentas, la consecuencia final fue, entonces, que ninguna prueba testimonial sin perjuicio de cuándo, cómo o dónde fuera colectada- sería válida en juicio si no se permitía al acusado confrontarla directamente. Ello comportó un enorme retroceso en la investigación de los casos de violencia doméstica, en virtud de las consabidas particularidades que presentan este tipo de hechos antes descriptas en este trabajo.

\subsection{Davis v. Washington y Hammon v. Indiana ${ }^{36}$}

La doctrina especializada del país norteamericano reclamó urgentemente remediar aquello. Así, existieron más tarde otros fallos que intentaron enmendar en algún punto los problemas que surgieron luego de Crawford, pero más a modo de parches. Los tres más importantes fueron, por un lado, Davis y Hammon y, posteriormente, Bryant. Cabe aclarar que al día de hoy se sigue exigiendo a la Corte Suprema que emita un nuevo fallo reparador que, en lugar de buscar soluciones temporales, directamente desacredite la doctrina Crawford del mismo modo que lo hizo con Roberts.

La Corte Suprema resolvió simultáneamente los casos Davis v. Washington y Hammon v. Indiana en un intento de responder a uno de los principales interrogantes surgidos con Crawford, a saber: si no es posible utilizar un testimonio no-confrontado en juicio, entonces

\footnotetext{
35 FISK, "Prosecution", cit. nota n 2, p. 256.

36 Resueltos conjuntamente en 547 U.S. 813 (2006).
} 
Polit. crim. Vol. 13, No 26 (Diciembre 2018) Art. 11, pp. 1055-1073.

[http://www.politicacriminal.cl/Vol_13/n_26/Vol13N26A11.pdf]

¿qué debe entenderse por testimonio? ¿Cuál es su naturaleza? ¿Qué manifestaciones caen dentro de esa definición?

En el caso Davis, la víctima de violencia doméstica había llamado al 911 por un episodio agresivo que estaba sucediéndose en ese momento. La policía de emergencias que la atendió le hizo una serie de preguntas tendientes a esclarecer el hecho delictivo en curso mientras se daba la comunicación. Con posterioridad la víctima no se presentó al juicio y el fiscal tuvo que aportar como prueba la grabación de aquel llamado al 911. La Corte Suprema validó la incorporación indirecta de este testimonio al juicio y ratificó la condena impuesta al acusado.

En cambio, en el precedente Hammon esas mismas preguntas de la policía a la víctima también efectuadas para esclarecer el hecho- fueron realizadas en otro contexto. Esto es, ya en el domicilio de la pareja, una vez culminada la situación violenta y separados él de ella en cuartos distintos, a efectos de realizar los respectivos interrogatorios. Controlada la situación, la mujer respondió el cuestionario policial bajo juramento (affidavit) dando a conocer lo que había sucedido un rato antes. Aquí la víctima tampoco se presentó al juicio y el fiscal aportó como prueba el testimonio colectado por los agentes policiales el día del hecho en su residencia. En este caso la Corte absolvió al imputado por aplicación de la cláusula de confrontación, en tanto éste no tuvo la oportunidad de enfrentar a la única testigo del hecho.

Con estos dos precedentes la Corte Suprema de EEUU diferenció dos tipos de situaciones, a saber: a) las manifestaciones que no tienen el carácter de declaración testimonial por el contexto en el que son vertidas, y que pueden utilizarse en juicio sin afectación de la cláusula de confrontación; $\mathrm{y}$, en cambio, b) las manifestaciones que sí tienen aquél carácter y que necesitan, por tanto, para admitirlas válidamente en juicio la posibilidad de confrontación por parte del imputado y/o su abogado.

La Corte concluyó, por un lado, que si la deposición fue durante los hechos y en una situación de emergencia en curso no tiene carácter testimonial, ya que la intención de su materialización no era la de armar el caso y las pruebas (prosecution), sino atender una situación de peligro que lógicamente imposibilitaba, desde el punto de vista material, el control de esa prueba por parte de la defensa mientras se estaba desarrollando. Por lo tanto, ese tipo de manifestaciones deben admitirse como una evidencia más en juicio.

Por otro lado, en cambio, si la declaración tiene como objeto reconstruir hechos pasados, sin que al momento de su materialización exista una situación de urgencia que deba neutralizarse, cuestión que permitiría un control de la defensa (estando presente el abogado, por ejemplo), entonces esta clase de declaraciones tienen estricto carácter testimonial y, por lo tanto, quedan comprendidas dentro de la cláusula de confrontación. Ergo, si el acusado no tiene o tuvo oportunidad de confrontar esta última clase de testimonios (sea en el momento de ser brindado o posteriormente) la prueba resultará, entonces, inadmisible en juicio.

Así, pues, estos dos casos permitieron precisar ciertas definiciones. Sobre todo, y en lo que aquí importa, con el caso Davis se admitió incorporar determinadas manifestaciones de la víctima que Crawford había prohibido: las vertidas en un contexto de necesidad y/o emergencia. 
VERGARA, Esteban. "La investigación sin víctima de ilícitos cometidos en contextos de violencia doméstica. Su situación actual en los Estados Unidos de América y el aporte a los países integrantes del Sistema Interamericano de Derechos Humanos”.

Sin embargo, ello no alcanzó para enmendar los problemas surgidos con Crawford. De hecho, lejos de solucionar la cuestión se terminó cayendo en el absurdo de que, si se quiere perseguir un caso de violencia sin todos estos inconvenientes, conviene que la víctima llame al 911 alegando urgencia en lugar de huir presurosamente del domicilio conyugal hacia la comisaría más próxima para resguardarse y ser asistida. Menos fructífero aún será presentarse a formular una denuncia formal en las oficinas públicas que pudieron crearse a tal fin con profesionales expertos en la materia. Es que, a partir de este fallo, se debe razonar que si una declaración es claramente testimonial, bajo los lineamientos dados, y constituye la única base de la fiscalía para tratar de esclarecer el hecho o la conexión del imputado con el delito, entonces aquélla será incompatible con el estándar constitucional en trato; y viceversa.

Si bien con ello se habrían cerrado las puertas se abrió, no obstante, una ventana. En efecto, en Davis, la Corte indicó que los tribunales tienen mecanismos para limitar el derecho a la confrontación, si la ausencia o reticencia del testigo se deriva de la mala conducta del imputado. En ese sentido, reconoció expresamente que en este tipo de crímenes particulares las víctimas son notoriamente susceptibles de ser intimidadas o coaccionadas para evitar su colaboración en el juicio. Así, se abrió un camino de excepción.

De todos modos, los casos Davis y Hammon no quedaron exentos de críticas. El nuevo interrogante surgido a partir de estos precedentes, siempre en pos de ampliar el callejón estrecho que creó la doctrina Crawford, fue la necesidad de definir qué debía entenderse por situación de emergencia o de necesidad, cuándo comienza y termina, etcétera. Para dar respuesta a dicho interrogante llegó el fallo Bryant, aunque lo hizo a medias.

\subsection{Bryant v. Michigan ${ }^{37}$}

Si bien este caso no tuvo lugar en un contexto de violencia doméstica, a diferencia de los anteriores, realizó un aporte importante al tema que nos convoca. Aquí, la policía llegó a una estación de servicio donde encontró a la víctima mortalmente herida en el suelo. Durante su agonía, les señaló a Bryant como quien minutos antes le había disparado y les indicó, además, que se encontraba armado en las inmediaciones del lugar. Al juicio solo pudieron concurrir los policías que intervinieron el día del hecho, ya que la víctima falleció a la postre por la agresión sufrida. Aquéllos atestiguaron lo que sabían de oídas (hearsay witnesses), es decir, lo que la víctima les había relatado mientras yacía en el suelo poco antes de morir. Finalmente, el tribunal condenó al acusado por homicidio y la Corte Suprema confirmó la decisión.

La doctrina que se extrajo de este fallo no fue que la manifestación que brindara la víctima era admisible porque había muerto (esto en sí, como vimos, no la transforma en admisible) sino la circunstancia de que sus dichos se habían dado en un contexto de emergencia o necesidad aun cuando la agresión ya había tenido lugar. En tal sentido, se amplió el concepto de Davis en punto a lo que debe entenderse por situación de emergencia en curso. Esto en tanto, si bien el disparo ya había ocurrido y el agresor se había alejado de la víctima, la situación de emergencia seguía vigente ya que el acusado continuaba en las inmediaciones,

${ }^{37} 131$ S. Ct. 1143 (2011). 
Polit. crim. Vol. 13, No 26 (Diciembre 2018) Art. 11, pp. 1055-1073.

[http://www.politicacriminal.cl/Vol_13/n_26/Vol13N26A11.pdf]

armado y peligroso, poniendo en riesgo la integridad de los policías y de terceras personas. Esa situación es la que lo diferencia del testimonio receptado en Hammon, pues en este caso la declaración tuvo por objeto reconstruir hechos pasados con fines eminentemente persecutorios y probatorios.

Así, la Corte Suprema concluyó que es válido el interrogatorio policial consistente en permitir que se resuelva una situación de emergencia o necesidad en curso, aun cuando ésta exceda a la víctima inicial o cuando la agresión ya tuvo lugar. Si bien este nuevo criterio no deja de ser una cuestión sujeta a apreciaciones subjetivas, al menos brinda otra posibilidad.

\section{Un paralelismo entre la doctrina de estos casos y la garantía del imputado a interrogar a los testigos en nuestra región}

La Convención Americana sobre Derechos Humanos establece, como garantía mínima, el derecho del imputado a interrogar a los testigos presentes en el tribunal y de obtener la comparecencia de otras personas que puedan arrojar luz sobre los hechos ${ }^{38}$. Esta prerrogativa, a priori, no pareciera ser tan rígida como la cláusula de confrontación, al menos desde su redacción. Lo que se dice pues, desde el punto de vista literal, permitiría la incorporación de testimonios por lectura (por caso, el brindado por una víctima de femicidio en su agonía) si se repara en que el derecho a repreguntar consagrado en la norma alude a los "testigos presentes en el tribunal". En otras palabras, podría interpretarse que lo que la norma prohíbe -positivamente- es cercenar de cualquier manera la participación plena de la defensa durante el debate, lo que de por sí no impide la posibilidad de que una parte incorpore testimonios escritos y a su vez se brinde a la contraparte la posibilidad de hacer lo mismo.

Sin embargo, a la manera de Crawford, los casos Castillo Petruzzi ${ }^{39}$ de la Corte IDH a nivel regional, y Benítez ${ }^{40}$ de la Corte Suprema de Justicia de la Nación en Argentina, nos presentan similares inconvenientes al interpretar aquella norma convencional. Ambos tribunales han coincidido en que dentro de las prerrogativas que deben concederse a quienes hayan sido acusados está la de examinar a los testigos en su contra y a favor, bajo las mismas condiciones, con el objeto de ejercer su defensa ${ }^{41}$. Es decir, el derecho a contrainterrogar fue extendido a todos los testigos de cargo, y no sólo a los presentes en el juicio. De hecho, el tribunal argentino fue más allá y expresamente asentó la prohibición de incorporar por lectura testimonios en contra del imputado si éste no ha tenido la posibilidad de confrontarlos, en tanto -argumentó- que ese proceder lesiona su derecho de defensa ${ }^{42}$.

Por su parte, las Guías de Santiago sobre protección de víctimas y testigos nos brindan cierto dilema. Primeramente, señalan que no se puede predicar de una manera uniforme principios comunes para abordar la intervención de la víctima en el momento mismo del juicio, ante la existencia de sistemas procesales diversos en nuestra región. Así también, dicen que allí donde tal intervención se dé, acatando las garantías procesales de todas las partes, se llevará

\footnotetext{
${ }^{38} \mathrm{CADH}$, Art. 8, 2, f.

${ }^{39}$ Corte IDH, Castillo Petruzzi y otros v. Perú, Sentencia del 30/05/1999.

40 CSJN, B.1147.XL., rta. 12/12/2006.

41 De la Corte IDH, párrafo. 154; de la CSJN, párrafo 15.

42 CSJN, B.1147.XL, Párrafo 16.
} 
VERGARA, Esteban. "La investigación sin víctima de ilícitos cometidos en contextos de violencia doméstica. Su situación actual en los Estados Unidos de América y el aporte a los países integrantes del Sistema Interamericano de Derechos Humanos”.

a cabo de forma respetuosa con la víctima para evitar consecuencias revictimizantes o que tal momento provoque que la misma pueda incluso abdicar de sus derechos para evitar la presión del momento ${ }^{43}$. Sin embargo, luego predican un rol de obligaciones para la víctima: una vez que el proceso tiene inicio, aquélla está obligada a colaborar con los operadores judiciales para el esclarecimiento de los hechos y la sanción de sus responsables ${ }^{44}$.

En suma, en América Latina es poco frecuente que se tenga clara conciencia acerca del valor de la confrontación. Siguiendo la línea de los precedentes antes citados se ha llegado a afirmar que es imposible confiar en información que no haya pasado por el test de la contradictoriedad $^{45}$. La cultura inquisitiva y el método del funcionario iluminado nos han llevado a prescindir durante mucho tiempo del cedazo de una contradictoriedad en serio ${ }^{46}$, lo que a su vez nos condujo a que hoy la incorporemos sin tener real dimensión de sus consecuencias -tanto positivas como negativas- en nuestros sistemas predominantemente mixtos.

De todo lo expuesto se colige que, en virtud de la fuerza que están tomando aquellos enfoques, en nuestra región se presentarán similares dificultades a las que existen en los Estados Unidos de América para llegar a buen puerto, si ya no han aparecido. De profundizarse aquellos criterios, resultará cada vez más difícil sancionar esta clase de hechos sin la víctima, sin importar el motivo de su ausencia. Esto se presenta como un problema, claro, en la medida en que los Estados del Sistema Interamericano han asumido el compromiso de prevenir, sancionar y erradicar la violencia contra la mujer ${ }^{47}$ siendo la persecución y castigo de los ilícitos cometidos por los tiranos domésticos un claro objetivo en ese camino.

\section{Hay luz al final del túnel}

Idealmente, se debe abogar por que las mujeres víctimas acompañen el juicio penal. Pero si esto no ocurre no debemos detenernos allí; ellas ya están transitando su propio proceso.

Aun cuando la situación no aparece sencilla, es posible advertir que nuestro territorio es suelo fértil para que broten recursos esperanzadores. Asimismo y trazando un paralelismo (teniendo siempre presente las diferencias sustanciales que existen entre el Common Law y el sistema continental), asoman herramientas que pueden ser utilizadas por los países que integran el Sistema Interamericano de Derechos Humanos a aquellos fines.

El sistema regional de Derechos Humanos viene señalando desde hace tiempo alternativas en miras de una salida al problema planteado. En ese sentido, la Corte IDH invita a apartarse

\footnotetext{
${ }^{43}$ Guías de Santiago sobre protección de víctimas y testigos, Capítulo Primero, acápite 5.f.

${ }^{44}$ Guías de Santiago sobre protección de víctimas y testigos, Capítulo Primero, acápite 5.g.

45 BAYTELMAN, Andrés; DUCE, Mauricio, "Litigación penal, juicio oral y prueba" en CASTILLO IBAÑEZ, Silvia (Coord.), Colección Derecho, Universidad Diego Portales: Santiago de Chile, 2004,p. 95.

46 BAYTELMAN, "Litigación”, p. 95.

47 Convención Interamericana para prevenir, sancionar y erradicar la violencia contra la mujer "Convención de Belem do Para".
} 
Polit. crim. Vol. 13, No 26 (Diciembre 2018) Art. 11, pp. 1055-1073.

[http://www.politicacriminal.cl/Vol_13/n_26/Vol13N26A11.pdf]

de los estándares probatorios tradicionales e imprimir a las investigaciones la perspectiva de género que este flagelo demanda ${ }^{48}$. Al respecto, resulta enriquecedor el cambio de paradigmas que dicho Tribunal viene sentando en sus fallos desde la década pasada, por caso en los conocidos precedentes "Miguel Castro Castro", "Pueblo Bello" o "Campo algodonero". Así, diversos tribunales superiores locales han receptado esa doctrina y la han aplicado a sus fallos en el último tiempo, mandando a los operadores judiciales a analizar estos casos con prudencia, garantizando la amplitud probatoria para acreditar los hechos denunciados, teniendo en cuenta las circunstancias especiales en las que se desarrollan los actos de violencia y quiénes son sus naturales testigos ${ }^{49}$.

Estos lineamientos aparecen como una enorme posibilidad para nuestros países, a diferencia de lo que ocurre en los EEUU que, al no haber ratificado el "Pacto de San José de Costa Rica", no se encuentra sometido a la jurisdicción de la Corte ni a dicha norma convencional.

Sobre ese atalaya surge la necesidad, ante la eventual imposibilidad de contar con la víctima en el juicio, de repensar la estrategia de investigación en hechos de esta naturaleza. En tal sentido, se debe robustecer el cuadro probatorio con otros indicios que permitan no sólo acreditar los ilícitos en sí, sino, además, el contexto de la víctima y de sus testimonios a efectos de dotarlos de mayor credibilidad y autosuficiencia, sobre todo en los albores de la investigación. Existen diversas herramientas para ello en nuestro sistema, como lo es el principio de la amplitud probatoria para la comprobación de esta clase de ilícitos -receptado en numerosas leyes ${ }^{50}$ y recogido por distintos tribunales ${ }^{51}$ - entre otras.

En esa inteligencia, el Comité de Expertas/os del MESECVI-OEA exhorta a realizar investigaciones prontas y exhaustivas teniendo en cuenta la situación preexistente de coercibilidad como elemento fundamental para determinar la existencia de la violencia, utilizando pruebas técnicas y prohibiendo explícitamente probanzas que se sustenten en la conducta de la víctima para inferir el consentimiento, tales como la falta de resistencia, la historia sexual o, sobre todo, la retractación durante el proceso ${ }^{52}$.

Paralelamente, también resulta por demás enriquecedora la teoría excepcional desarrollada por la Corte Suprema de los Estados Unidos en el caso Davis, en torno a sopesar la influencia

\footnotetext{
${ }^{48}$ En este norte, resulta enriquecedor el cambio de paradigmas que la Corte IDH viene sentando en sus fallos desde la década pasada, por caso en los conocidos precedentes "Miguel Castro Castro", "Pueblo Bello" o "Campo algodonero".

${ }^{49}$ Tribunal Superior de Justicia de la Ciudad Autónoma de Buenos Aires, Expte. n8796/12, "Newbery Greve", del 11/09/13, entre otros.

${ }^{50}$ Vgr: la Ley Nacional de Protección Integral a las Mujeres $n^{\circ}$ 26.485; Decreto Nacional $n^{\circ} 1011 / 10$; el art. 106 del Código Procesal Penal de la Ciudad Autónoma de Buenos Aires; o la Ley de la CABA n 4.203.

${ }^{51}$ Vgr: Tribunal Superior de Justicia de la Ciudad Autónoma de Buenos Aires, in re ob.cit. "Newbery Greve"; in re "Taranco", Expte. 9510/13, rta. 22/04/14; y recientemente in re "Scarnato", Expte. 13751/16, rta. 13/09/17. Cámara Nacional de Casación Penal de Argentina, Sala II, in re "Origüela Condori”, Expte. 13685, rta. 25/10/12; y Sala IV, in re “Abolio", Expte. 1841/13, rta. 01/10/14.

${ }^{52}$ Comité de Expertas/os (CEVI) del Mecanismo de Seguimiento de la Implementación de la Convención Interamericana para Prevenir, Sancionar y Erradicar la Violencia Contra la Mujer, "Convención de Belém do Pará" (MESECVI). "Declaración sobre la Violencia contra las Mujeres, Niñas y Adolescentes y sus Derechos Sexuales y Reproductivos". OEA/Ser.L/II.7.10 MESECVI/CEVI/DEC.4/14. Del 19/09/14.
} 
VERGARA, Esteban. "La investigación sin víctima de ilícitos cometidos en contextos de violencia doméstica. Su situación actual en los Estados Unidos de América y el aporte a los países integrantes del Sistema Interamericano de Derechos Humanos”.

eventual del acusado en el desistimiento de la víctima para prescindir de su presencia. En efecto, es dable afirmar que la reticencia de las víctimas a acompañar el proceso muchas veces obedece, casi directa y exclusivamente, al comportamiento del agresor (que en muchos casos requerirá del recurso a la prisión preventiva para proteger a la víctima en este tipo de situaciones). Partiendo de esa premisa, se podrá profundizar en aquella doctrina de excepción norteamericana y volcarla a nuestro suelo satisfactoriamente y con enormes beneficios.

Asimismo, es posible sostener que en nuestros países estamos frente a la gran posibilidad de sacar provecho de los lineamientos del caso Roberts y su test, y aplicarlos en nuestros sistemas judiciales. Las limitaciones surgidas a la doctrina Crawford lo resucitan de alguna manera. Cuanto menos, en lo que hace a la posibilidad -aun excepcional- de hacer valer el testimonio de las víctimas ausentes en el juicio, si se lo refuerza con otra prueba. Será cuestión de incorporarlos y afianzarlos hasta donde sea posible, siempre en franco respeto a las garantías judiciales imperantes en los procesos penales latinoamericanos ${ }^{53}$, conjugadas con las obligaciones internacionales asumidas por nuestros países en materia de violencia doméstica $^{54}$. Ello no significa en modo alguno dejar de lado las prerrogativas esenciales de todo acusado. Debemos ser cuidadosos con los principios de oralidad, publicidad e inmediación reinantes en muchos de nuestros ordenamientos ${ }^{55}$, como así también con el debido proceso legal y la defensa en juicio materializada en el derecho del imputado de confrontar la prueba de cargo en su contra ${ }^{56}$.

Pero, al mismo tiempo, también es nuestra obligación asumir la responsabilidad que existe sobre nuestros hombros frente a las víctimas de violencia doméstica y de género.

\section{Conclusiones}

En función de lo expuesto, es posible advertir en la actualidad la magnitud y trascendencia que se da en los sistemas judiciales del continente a la colaboración de la víctima durante el proceso, así como también las negativas consecuencias a las que se arriba cuando esa cooperación no ocurre.

Reconociendo ese flagelo, el caso Crawford fue criticado severamente por los inconvenientes que trajo al sistema judicial norteamericano a la hora de investigar hechos de violencia doméstica. Ello, en resumidas cuentas, porque excluía la incorporación por lectura de prueba testimonial, que antes estaba permitida, por resultar contraria a la cláusula de confrontación.

Posteriormente, estos obstáculos fueron mitigados en parte, gracias a los casos Davis, Hammon y Bryant, aunque el problema de fondo quedó subsistente.

\footnotetext{
${ }^{53}$ En virtud de las diferencias entre nuestro sistema y el Common Law inglés.

54 Por caso mediante la "Convención de Belém do Pará", consagrado por la Corte Suprema Argentina in re "Góngora" (G.61.XLVIII).

55 Constitución de la Nación Argentina, art. 18; Constitución de la Ciudad Autónoma de Buenos Aires, art. 13; CADH, art. 8.2.f; PIDCyP, art. 14.3.e.

${ }^{56}$ En el ámbito de la Ciudad de Buenos Aires, por caso, a través del art. 239 de su Código Procesal Penal.
} 
Polit. crim. Vol. 13, No 26 (Diciembre 2018) Art. 11, pp. 1055-1073.

[http://www.politicacriminal.cl/Vol_13/n_26/Vol13N26A11.pdf]

Los casos más impactados por estos cambios jurisprudenciales en el sistema judicial anglosajón fueron, sin dudas, los de violencia doméstica y/o de género. Ello se debe, como señalamos al inicio del presente artículo, a que las víctimas de estos hechos son más propensas a retractarse de sus denuncias que los afectados por otros delitos o también tienden a no testificar con el avance del procedimiento.

Paralelamente, se advirtió que en los países latinoamericanos está sucediendo algo similar. Las víctimas ausentes en los juicios dificultan la obtención de resultados fructíferos, lo cual pone en duda el real esfuerzo que vienen desarrollando los sistemas judiciales en la lucha contra la violencia doméstica contra las mujeres.

Por ello, resulta imperioso dotar a los procedimientos de la región de nuevas herramientas y conferirles de un modo más concreto la perspectiva de género consagrada por el Sistema Interamericano de Derechos Humanos, con sus cambios de paradigmas en materia probatoria, y la celeridad demandada.

Sobre esa línea, se podrá llegar a buen puerto aun prescindiendo de la víctima mediante la utilización de los lineamientos del Roberts Test conjugado con o simultáneo a lo que, a los fines de este artículo, podrá llamarse Davis Test, consistente en sopesar la influencia eventual del acusado en el desistimiento de la víctima para restringir -siempre dentro de un marco de garantías vigentes- el derecho del imputado a la confrontación directa en el juicio. Esto podrá constituir un puntapié inicial para la profundización de esas herramientas y la creación de otros recursos que permitan ya no solo avanzar en las investigaciones sino -igualmente importante- comprender, de una vez por todas, la situación de las víctimas sometidas a procesos penales y evitar así su constante revictimización.

El deber de investigar no es una obligación de resultados sino de medios, aunque éstos no deben ser ajenos a aquéllos. Por ello, los Estados deben asumirlo como un compromiso jurídico propio y no como una simple formalidad condenada de antemano al fracaso. La obligación de los Estados de investigar debe cumplirse de manera eficiente para evitar la impunidad e impedir que este tipo de hechos se repitan ${ }^{57}$. A partir de allí se podrán desterrar -al menos paulatinamente- los obstáculos que hoy se presentan en las investigaciones de ilícitos cometidos en el contexto de la violencia doméstica. Todo ello, con la premura que estos hechos exigen, antes de que pueda aparecer un nuevo Crawford por estas latitudes.

${ }^{57}$ Corte Interamericana de Derechos Humanos, caso "González y otras-Campo Algodonero- vs. México", del 16/11/2009, p.289. En el mismo sentido, Corte Suprema de Justicia argentina in re "Góngora" (G.61.XLVIII), considerando $7^{\circ}$. 
VERGARA, Esteban. "La investigación sin víctima de ilícitos cometidos en contextos de violencia doméstica. Su situación actual en los Estados Unidos de América y el aporte a los países integrantes del Sistema Interamericano de Derechos Humanos”.

\section{Bibliografía}

BAYTELMAN, Andrés; DUCE, Mauricio, "Litigación penal, juicio oral y prueba" en CASTILlO IBAÑEZ, Silvia (Coord.), Colección Derecho, Universidad Diego Portales: Santiago de Chile, 2004, pp. 95-123.

BINSTOK, Hanna, "Violencia en la pareja", Serie Mujer y Desarrollo, n 23 (1998) en: https://repositorio.cepal.org/bitstream/handle/11362/5896/1/S026408_es.pdf.

BUNGE CAMPOS, Luis María, “Cross Examination”, Lecciones y Ensayos, n 63 (1995) en: http://www.derecho.uba.ar/publicaciones/lye/revistas/63/cross-examination.pdf.

CRUMP, David, "Overruling Crawford v. Washington: Why and How", Notre Dame L. Rev. $\mathrm{N}^{\mathrm{o}} 115$ (2012), pp.115-157

FISK, Andrew, "Prosecution of Domestic Violence Cases: The Practical Effects of the Ruling in Davis v. Washington", 126 S.Ct.2266 (2006), HeinOnline, 32 S. III. U. L.J. 251 2007-2008, Vol. 32,pp. 251-268

PERCIVAL, Jeanine, "The price of silence: The prosecution of domestic violence cases in light of Crawford v. Washington", Southern California Law Review Domestic Violence, Vol. 79:213, pp. 213-264

POPKIN, Margaret, Directora Ejecutiva de la Fundación para el Debido Proceso Legal, Washington, D.C., en "La difusión de las sentencias en Estados Unidos”, ponencia presentada en Sinaloa y Tabasco, 2004, en: https://archivos.juridicas.unam.mx/www/bjv/libros/4/1646/10.pdf.

RUBANO LAPASTA, Mariela, "El sistema del Common Law en el derecho inglés y el derecho de los Estados Unidos de América", Revista de la Facultad de Derecho, Universidad de la República, Uruguay, p. 70, en: revista.fder.edu.uy/index.php/rfd/article/download/268/291. 